\title{
Plasmin-Induced Redistribution of Platelet Glycoprotein Ib
}

\author{
By Alan D. Michelson and Marc R. Barnard
}

Platelet membrane glycoprotein lb (GPIb), a receptor for von Willebrand factor and thrombin, is present on the platelet surface membrane, in intraplatelet stores, and in plasma (as the proteolytic fragment glycocalicin). We examined the hypothesis that after plasmin-mediated cleavage of platelet surface GPIb, platelets can replenish their surface GPIb pool. Incubation of washed platelets with plasmin $\left(1\right.$ hour, $22^{\circ} \mathrm{C}$ ) resulted in loss of platelet surface GPIb, but further incubation $\left(3\right.$ hours, $\left.37^{\circ} \mathrm{C}\right)$ in autologous plasma resulted in restoration of platelet surface GPIb, as determined by ristocetin-induced platelet agglutination and a flow cytometric assay of platelet binding of three GPIb-specific monoclonal antibodies. Despite the restoration of platelet surface GPlb after the 3-hour incubation of plasmin-treated platelets in autologous plasma, the whole

$\mathbf{P}$ LATELET MEMBRANE glycoprotein (GP) Ib has binding domains for von Willebrand factor ( $\mathrm{VWF})^{1-3}$ and thrombin ${ }^{4,5}$ and is thus important in adhesion of platelets to damaged blood vessel walls and the interaction of platelets with the coagulation system. ${ }^{6} \mathrm{GPIb}$ is present on the platelet surface membrane, ${ }^{6}$ in intraplatelet stores, ${ }^{7}$ and in plasma (as the proteolytic fragment glycocalicin). ${ }^{8}$ Thrombin induces a downregulation of platelet surface GPIb ${ }^{9-11}$ that may be the result of translocation of platelet surface GPIb to the intraplatelet pool. ${ }^{12}$ In contrast, we recently demonstrated that during in vitro storage of platelets, GPIb molecules are redistributed in the direction of intraplatelet to platelet surface to plasma pools.?

Plasmin has been shown to proteolyse platelet surface GPIb, with release of glycocalicin into the supernatant. ${ }^{13-15}$ In the present study, we examined the hypothesis that after plasmin-mediated cleavage of platelet surface GPIb, platelets can replenish their surface GPIb pool by recruitment of GPIb molecules from the intraplatelet pool.

\section{MATERIALS AND METHODS}

Monoclonal antibodies. 6D1 (provided by Dr Barry S. Coller, SUNY, Stony Brook, NY) is a murine IgG monoclonal antibody (MoAb) directed at the $\mathrm{vWf}$ binding site on the glycocalicin portion of the $\alpha$-chain of GPIb. ${ }^{1,2}$ WM23 and AK3 (provided by Dr Michael C. Berndt, University of Sydney, Australia) are both murine IgG MoAbs directed at the macroglycopeptide portion of glycocalicin, rather than the $\mathrm{N}$-terminal protein portion that contains the vWF and 6D1 binding sites. ${ }^{16.17}$ S12 (provided by Dr Rodger P. McEver, University of Oklahoma) is a murine IgG MoAb directed against GMP-140. ${ }^{18}$ GMP-140, also referred to as platelet activationdependent granule-external membrane (PADGEM) protein, ${ }^{19}$ is a component of the $\alpha$-granule membrane of resting platelets that is expressed on the platelet plasma membrane only after platelet activation and secretion. ${ }^{18}$

Incubation of plasmin-treated platelets in autologous plasma. Peripheral venous blood obtained from healthy volunteers was drawn into a syringe containing one-seventh volume of acid-citrate-dextrose (trisodium citrate $85 \mathrm{mmol} / \mathrm{L}$, citric acid $71 \mathrm{mmol} / \mathrm{L}$, dextrose 111 $\mathrm{mmol} / \mathrm{L}, \mathrm{pH} 4.5$ ) resulting in a final $\mathrm{pH}$ of 6.5 , as previously described. ${ }^{20}$ Platelet-rich plasma (PRP) was then prepared as previously described. ${ }^{10}$ Autologous plasma was prepared by centrifugation of the remaining blood $\left(2,000 \mathrm{~g}, 10\right.$ minutes, $\left.22^{\circ} \mathrm{C}\right)$, removal of the upper two-thirds of the supernatant, and adjustment of the $\mathrm{pH}$ platelet GPlb content (measured by enzyme-linked immunosorbent assay [ELISA], sodium dodecyl sulfate-polyacrylamide gel electrophoresis, and flow cytometry) remained reduced, quantitatively corresponding to an increase in plasma glycocalicin concentration (measured by ELISA). The loss and restoration of platelet surface GPlb occurred on all platelets and, as evidenced by lack of inhibition by prostaglandin $E_{1}$, EDTA, and cytochalasins, was not mediated by cyclic AMP, extracellular $\mathrm{Ca}^{2+}$, or the platelet microfilament system. In summary, this study shows that after plasmin-mediated cleavage of platelet surface GPIb, platelets can replenish their surface GPIb pool by recruitment of GPIb molecules from the intraplatelet pool (or from a sequestered surface site).

(C) 1990 by The American Society of Hematology.

to 7.2 with $1 \mathrm{~mol} / \mathrm{L} \mathrm{NaOH}$. A suspension of platelets was obtained from the PRP by washing it twice in modified Tyrode's buffer [138 $\mathrm{mmol} / \mathrm{L} \mathrm{NaCl}, 2.9 \mathrm{mmol} / \mathrm{L} \mathrm{KCl}, 12 \mathrm{mmol} / \mathrm{L} \mathrm{NaHCO}, 0.4$ $\mathrm{mmol} / \mathrm{L} \mathrm{NaHPO}, 0.1 \%$ glucose, $0.35 \%$ bovine serum albumin (BSA), $\mathrm{pH}$ 6.5] with $50 \mathrm{ng} / \mathrm{mL}$ prostaglandin $\mathrm{E}_{1}\left(\mathrm{PGE}_{1}\right)$, as previously described. ${ }^{10}$ The final resuspension of platelets was in modified Tyrode's buffer, $\mathrm{pH} 7.3$, with $50 \mathrm{ng} / \mathrm{mL} \mathrm{PGE}$ and 1 mmol/L EDTA. In other experiments, the final resuspension of platelets was in modified Tyrode's buffer, $\mathrm{pH} 7.3$, with $1 \mathrm{mmol} / \mathrm{L}$ $\mathrm{CaCl}_{2}$. The platelets $\left(5 \times 10^{5} / \mu \mathrm{L}\right)$ were then incubated $(1$ hour, $22^{\circ} \mathrm{C}$ ) with various concentrations of freshly reconstituted plasmin (KABI through Helena Laboratories, Beaumont, TX). Control samples were incubated without plasmin. Plasmin digestion was inhibited by adding to all samples an equal volume of autologous plasma; the samples were incubated for 3 hours at $37^{\circ} \mathrm{C}$. In some experiments, one of the following was included in the 3-hour incubation: (a) $6 \mu \mathrm{mol} / \mathrm{L}$ cytochalasin B (Sigma, St Louis, MO) in $0.4 \%$ dimethyl sulfoxide (DMSO) (Sigma), (b) $0.75 \mu \mathrm{mol} / \mathrm{L}$ cytochalasin D (Sigma) in $0.4 \%$ DMSO, (c) $0.4 \%$ DMSO, or (d) buffer only. At various time points, aliquots were withdrawn and were either (a) fixed with $1 \%$ formaldehyde as previously described ${ }^{20}$ and assayed by flow cytometry for either platelet surface GPIb or whole platelet GPIb content; (b) assayed for whole platelet GPIb content by either enzyme-linked immunosorbent assay (ELISA) or sodium dodecyl sulfate-polyacrylamide gel electrophoresis (SDS-PAGE); (c) analyzed for ristocetin-induced platelet agglutination; or (d) centrifuged $\left(8,000 \mathrm{~g}, 10\right.$ minutes, $\left.22^{\circ} \mathrm{C}\right)$, after which the upper

From the Department of Pediatrics, University of Massachusetts Medical School, Worcester, MA.

Submitted September 25, 1989; accepted June 20, 1990.

Supported by FIRST Award HL38138 from the National Institutes of Health, Bethesda, MD, (to A.D.M.), a grant from the American Heart Association, Massachusetts Affiliate, and Basil O'Connor Starter Scholar Research Award No. 5-582 from the March of Dimes Birth Defects Foundation.

Address reprint requests to Alan D. Michelson, MBBS, Department of Pediatrics, University of Massachusetts Medical School, 55 Lake Ave N, Worcester, MA 01655.

The publication costs of this article were defrayed in part by page charge payment. This article must therefore be hereby marked "advertisement" in accordance with 18 U.S.C. section 1734 solely to indicate this fact.

(c) 1990 by The American Society of Hematology.

0006-4971/90/7610-0125\$3.00/0 
two-thirds of the supernatant was removed and assayed for glycocalicin by ELISA.

Plasma glycocalicin determined by ELISA. The ELISA method has been described previously., A monolayer of platelets was fixed to plastic microwells, and the ability of diluted plasma samples to inhibit the binding of monoclonal antibody 6D1 to platelet surface GPIb was compared with a standard curve of the inhibition of 6D1 binding by known nanomolar concentrations of purified glycocalicin. All assays were performed in triplicate. We previously demonstrated ${ }^{7}$ that centrifugation of plasma at $22^{\circ} \mathrm{C}$ for 2 hours at $100,000 \mathrm{~g}$ (ie, at forces in excess of those required to sediment platelets and microparticles ${ }^{21}$ ) results in no change in the glycocalicin content of the supernatant, as determined by ELISA. Thus, the ELISA measures only soluble glycocalicin, not microparticle-associated glycocalicin or GPIb.

Ristocetin-induced platelet agglutination. Platelets (250,000/ $\mu \mathrm{L}$ ) suspended in autologous plasma were stirred with $1.2 \mathrm{mg} / \mathrm{mL}$ ristocetin (BioData, Horsham, PA) in a Lumi-Aggregation Module series 10008 (Payton, Buffalo, NY). Platelet agglutination was detected by change in light transmission, as previously described. ${ }^{14}$

Platelet surface GPIb determined by flow cytometry. The flow cytometry method has been described previously. ${ }^{7,10,20}$ Formaldehydefixed platelets were washed, incubated with a saturating concentration of a MoAb (6D1, WM23, or AK3), washed, incubated with a saturating concentration of fluorescein isothiocyanate (FITC)labeled goat antimouse IgG antibody (Cooper Biomedical, Malvern, PA), washed, and analyzed in either a FACS 440 (Becton Dickinson FACS Systems, Mountain View, CA) or an EPICS Profile flow cytometer (Coulter Cytometry, Hialeah, FL). For each sample, the fluorescence signal from 10,000 individual cells was measured. Background binding obtained from parallel assays with the irrelevant MoAb OX6 was subtracted from each sample.

Whole platelet GPIb content determined by flow cytometry. Formaldehyde-fixed platelets $(25,000 / \mu \mathrm{L})$ were incubated (30 minutes, $22^{\circ} \mathrm{C}$ ) with FITC-labeled MoAb 6D1 (in sevenfold excess of the saturating concentration for platelet surface GPIb) or FITClabeled mouse IgG (Jackson ImmunoResearch, West Grove, PA) and $0.1 \%$ Triton X-100 (Sigma) in phosphate-buffered saline (PBS, $137 \mathrm{mmol} / \mathrm{L} \mathrm{NaCl}, 2.7 \mathrm{mmol} / \mathrm{L} \mathrm{KCl}, 1.5 \mathrm{mmol} / \mathrm{L} \mathrm{KH}_{2} \mathrm{PO}_{4}, 8.1$ $\left.\mathrm{mmol} / \mathrm{L} \mathrm{Na}_{2} \mathrm{HPO}_{4}, \mathrm{pH} 7.4\right)$ with $0.35 \% \mathrm{BSA}$ and then diluted 10 -fold in PBS with $0.35 \%$ BSA. Nonpermeabilized controls were prepared identically except that Triton X-100 was omitted. The samples were analyzed in an EPICS Profile flow cytometer. For each sample, the fluorescence signal from 10,000 individual cells was measured. Background binding obtained from parallel assays with the mouse IgG was subtracted from each sample. The fluorescence intensity of $1 \%$ formaldehyde-fixed platelets was $26.5 \% \pm 1.8 \%$ (mean \pm SEM, $n=3$ ) lower than unfixed samples, demonstrating that formaldehyde fixation did not permeabilize the platelets. During graded Serratia protease cleavage of platelet surface GPIb, ${ }^{22}$ the mean fluorescence intensity of fixed platelets plotted as a function of the fluorescence intensity of equivalent unfixed samples generated a straight line that passed through the origin, thereby demonstrating that fixation did not interfere with quantitation in this assay. Treatment of 6D1-labeled, washed, nonpermeabilized platelets with $0.1 \%$ Triton $\mathrm{X}-100$ for 30 minutes at $22^{\circ} \mathrm{C}$ did not diminish the fluorescence signal as compared with platelets not treated with Triton, demonstrating that $0.1 \%$ Triton $\mathrm{X}-100$ treatment of fixed platelets did not result in extraction of the 6D1 epitope. As determined by flow cytometry, the whole platelet GPIb content was $286.0 \% \pm 9.4 \%($ mean \pm SEM, $n=3$ ) of the platelet surface GPIb pool. That the whole platelet GPIb content was less by this intact platelet method than as determined from solubilized platelets by ELISA and SDS-PAGE methods ${ }^{\gamma}$ probably reflects one or more of the following ${ }^{23}$ : decreased accessibility of intracellular antigen because of cross-linking of surrounding protein matrix, a different fixation-induced loss of immunoreactivity for intracellular and platelet surface antigen, or self-quenching of fluorescence owing to close packing of intracellular antigen.

Whole platelet GPIb content determined by ELISA. The ELISA method has been described previously. ${ }^{7}$ The platelets were washed in modified Tyrode's buffer and lysed by addition of an equal volume of buffer containing $2 \%$ Triton X-100 (Sigma), $100 \mathrm{mmol} / \mathrm{L}$ Tris-HCl, pH 7.4, with $2 \mathrm{mg} / \mathrm{mL}$ leupeptin (Sigma). The samples were then centrifuged at $8,000 \mathrm{~g}$ for 4 minutes, conditions that do not sediment most of the actin filament-associated GPIb. ${ }^{7.24}$ The resulting supernatants were assessed by ELISA (as described above) for their ability to inhibit MoAb 6D1 binding to platelet surface GPIb. Each platelet lysate was assayed at two dilutions, three times each.

Whole platelet GPIb content determined by SDS-PAGE. The SDS-PAGE method has been described previously. ${ }^{7}$ Washed whole platelets were subjected to SDS-PAGE (with $5 \%$ polyacrylamide), stained with periodic acid-Schiff's reagent, and analyzed by a video image processing system with Imagemeasure (Microscience, Federal Way, WA), and the amount of GPIb was calculated. ${ }^{7}$

Thrombin-induced downregulation of platelet surface GPIb determined by flow cytometry. The flow cytometry method, which used purified human $\alpha$-thrombin (provided by Dr John Fenton II, New York Department of Health, Albany, NY), has been described previously. ${ }^{10}$

\section{RESULTS}

We wished to determine whether platelets can replenish the surface GPIb pool after plasmin-mediated cleavage of platelet surface GPIb. First, we incubated washed platelets with plasmin for 1 hour at $22^{\circ} \mathrm{C}$. Increasing concentrations of plasmin resulted in decreasing degrees of ristocetin-induced platelet agglutination, as determined by a standard nephelometric technique (Fig 1, 0 time point). Plasmin digestion was then inhibited by addition of an equal volume of autologous plasma, and the samples were incubated for 3 more hours at $37^{\circ} \mathrm{C}$. This incubation resulted in a gradual recovery of ristocetin-induced platelet agglutination (Fig 1).

To confirm that this effect was the result of a change in platelet surface GPIb, aliquots of the same samples were assessed by flow cytometry using two GPIb-specific MoAbs (WM23 and 6D1). Incubation with plasmin resulted in a decrease in the platelet surface expression of GPIb that paralleled the decrease in ristocetin-induced platelet agglutination (Fig 2). The subsequent incubation in autologous plasma resulted in a gradual restoration of the platelet surface expression of GPIb, the kinetics of which paralleled the return of ristocetin-induced platelet agglutination (Fig 2).

Performance of these experiments without $\mathrm{PGE}_{1}$ and with $1 \mathrm{mmol} / \mathrm{L} \mathrm{CaCl}_{2}$ rather than $1 \mathrm{mmol} / \mathrm{L}$ EDTA, resulted in a similar restoration of platelet surface GPIb expression, as determined by both ristocetin-induced platelet agglutination and flow cytometry with antibodies WM23 and 6D1 (data not shown).

The ability of the flow cytometric technique to analyze individual platelets ${ }^{20}$ enabled us to determine that the loss and restoration of platelet surface GPIb expression was not confined to a subpopulation of platelets but occurred to a similar extent on all platelets (Fig 3).

To determine whether GPIb molecules were redistributed between the intraplatelet and plasma pools, aliquots of the same samples were analyzed by ELISA for whole platelet 


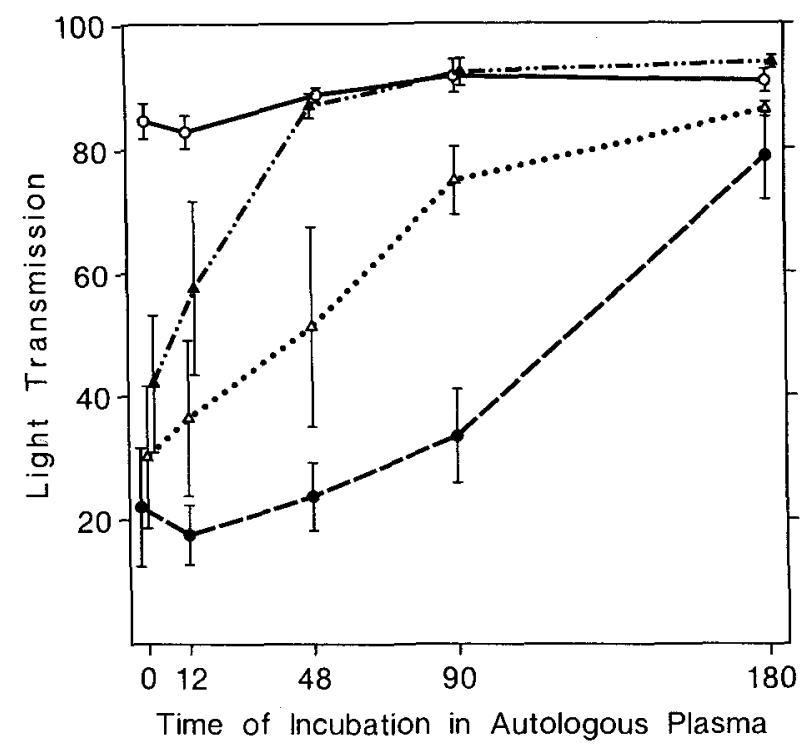

(minutes)

Fig 1. Effect on ristocetin-induced platelet agglutination of incubation of plasmin-treated platelets in autologous plasma. Washed platelets suspended in modified Tyrode's buffer, pH 7.3, with $50 \mathrm{ng} / \mathrm{mL}$ PGE, and $1 \mathrm{mmol} / \mathrm{L}$ EDTA, were incubated with plasmin for 1 hour at $22^{\circ} \mathrm{C}$. Plasmin digestion was inhibited by the addition of autologous plasma and the samples were incubated for 3 hours at $37^{\circ} \mathrm{C}$. At the indicated time points, samples were incubated with ristocetin $1.2 \mathrm{mg} / \mathrm{mL}$ in an aggregometer and maximal agglutination was determined by light transmission. Open circles, solid triangles, open triangles, and solid circles represent platelets incubated with plasmin $0,0.03125,0.0625$, and 0.125 $\mathrm{CU} / \mathrm{mL}$, respectively. Data are mean \pm SEM from three separate experiments.

GPIb content and for glycocalicin released into the plasma medium (Table 1). Although 3 hours of incubation of plasmin-treated platelets in autologous plasma resulted in restoration of platelet surface GPIb (Figs 1 through 3), the whole platelet GPIb content was reduced in proportion with the observed increase in the glycocalicin concentration of the plasma medium (Table 1). There were no significant changes in platelet counts during these experiments.

SDS-PAGE and flow cytometric analysis of permeabilized platelets were used to verify by independent methods that incubation of plasmin-treated platelets in autologous plasma can result in a redistribution of GPIb molecules between intraplatelet and platelet surface pools. During a 1-hour incubation, plasmin $0.125 \mathrm{CU} / \mathrm{mL}$ resulted in a loss of platelet surface GPIb (Fig 4A) and a reduction in whole platelet GPIb content (Fig 4B). The loss of whole platelet GPIb content with plasmin $0.125 \mathrm{CU} / \mathrm{mL}$ was approximately $50 \%$, whether the whole platelet GPIb content was measured by flow cytometric analysis of permeabilized platelets (Fig 4B), SDS-PAGE (Fig 4B), or ELISA (Table 1). As determined by flow cytometry, the decrease in the whole platelet GPIb content was not confined to a subpopulation of platelets but occurred to a similar extent on all platelets (data not shown). After a 3-hour incubation in autologous plasma, there was some replenishment of the platelet surface GPIb pool (Fig 4A) but no change in the whole platelet GPIb content, as determined by both
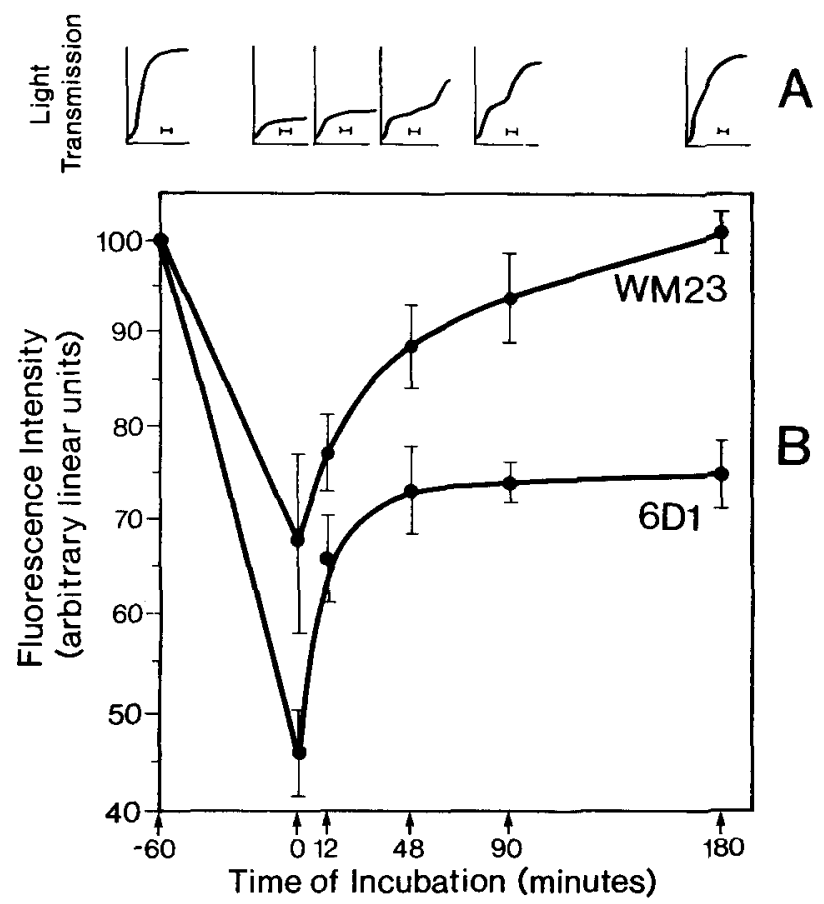

\begin{tabular}{|c|c|}
\hline Plasmin \\
Incubation
\end{tabular}

Fig 2. Effect on platelet surface GPIb of incubation of plasmintreated platelets in autologous plasma. Conditions were as described in the legend to Fig 1, with plasmin $0.0625 \mathrm{CU} / \mathrm{mL}$. (A) Ristocetin-induced platelet agglutination. The horizontal bar in each agglutination tracing represents 1 minute. (B) Flow cytometry. For each of the GPIb-specific monoclonal antibodies (WM23 and 6D1), the fluorescence intensity of platelets before plesmin incubation was assigned $100 \mathrm{U}$. Flow cytometric data are mean \pm SEM from three separate experiments.

SDS-PAGE and flow cytometry (Fig 4B). There were no significant changes in platelet counts during these experiments.

To determine whether the platelet microfilament system

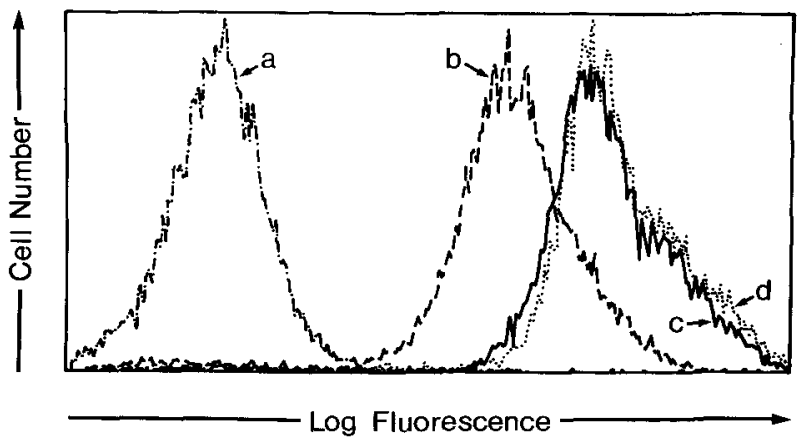

Fig 3. Effect on platelet surface GPIb of incubation of plasmintreated platelets in autologous plasma, as determined by flow cytometry. Conditions were as described in Fig 1. Platelets incubated with normal mouse IgG, ie, background (a); platelets incubated with the GPIb-specific MoAb WM23 (b through d): platelets after 1-hour incubation with plasmin $0.0625 \mathrm{CU} / \mathrm{mL}$ (b); same platelets as in $b$ but after 90 -minute incubation in autologous plasma (c); control platelets, ie. platelets incubated identically to those in c except without plasmin treatment (d). The experiment was representative of three separate experiments. 
Table 1. Effect on Whole Platelet GPIb Content and Released Glycocalicin of Plasmin Treatment of Washed Platelets Followed by Incubation in Autologous Plasma

\begin{tabular}{lccc}
\hline \multirow{2}{*}{$\begin{array}{c}\text { Plasmin } \\
\text { Concentration } \\
\text { (CU/mL) }\end{array}$} & Whole Platelet & $\begin{array}{c}\text { GPib Content (molecules/platelet) } \\
\text { Plasmin-Mediated Release } \\
\text { of Glycocalicin into } \\
\text { Plasma Medium }\end{array}$ & $\begin{array}{c}\text { Total (whole } \\
\text { platelet plus } \\
\text { released) }\end{array}$ \\
\hline 0 & $184,000 \pm 26,000$ & $0^{*}$ & $184,000 \pm 26,000$ \\
0.03125 & $150,000 \pm 16,000$ & $39,000 \pm 8,000$ & $189,000 \pm 24,000$ \\
0.0625 & $122,000 \pm 7,000$ & $61,000 \pm 9,000$ & $183,000 \pm 8,000$ \\
0.125 & $91,000 \pm 12,000$ & $97,000 \pm 5,000$ & $188,000 \pm 14,000$ \\
\hline
\end{tabular}

Washed platelets were incubated with plasmin or buffer for 1 hour at $22^{\circ} \mathrm{C}$ and then with an equal volume of autologous plasma for 3 hours at $37^{\circ} \mathrm{C}$. Whole platelet GPIb content and plasma glycocalicin were then determined by ELISA using MoAb 6D1. These data were obtained from the same experiments shown in Figs. 1 through 3. Mean \pm SEM, $n=3$ separate experiments.

- Plasmin-mediated release of glycocalicin into plasma medium was calculated by subtraction of the glycocalicin content of the medium of the non-plasmin-treated platelet sample: $22.4 \pm 6.2 \mathrm{nmol} / \mathrm{L}$, or $54,000 \pm 8,000$ molecules per platelet (of which $50,000 \pm 9,000$ molecules per platelet derived from plasma and 4,000 $\pm 3,000$ molecules per platelet was shed from platelets).

had a role in the plasmin-induced redistribution of GPIb molecules, experiments were performed in which cytochalasins (inhibitors of actin polymerization ${ }^{25}$ ) were added to the autologous plasma incubation. As shown in Fig 4A and B, 6 $\mu \mathrm{mol} / \mathrm{L}$ cytochalasin B had no effect on redistribution of GPIb to the surface. In parallel samples, $6 \mu \mathrm{mol} / \mathrm{L}$ cytochalasin B did affect human $\alpha$-thrombin-induced downregulation of platelet surface GPIb expression. In the presence of DMSO only, thrombin $1.0 \mathrm{U} / \mathrm{mL}$ induced reductions of 95.3\% and $92.4 \%$ in the platelet surface binding of antibodies 6D1 and AK3, respectively. With DMSO and cytochalasin B added, thrombin $1.0 \mathrm{U} / \mathrm{mL}$ induced reductions of only $27.5 \%$ and $22.7 \%$ in the binding of $6 \mathrm{D} 1$ and $\mathrm{AK} 3$, respectively. In both the plasmin and thrombin experiments, $0.75 \mu \mathrm{mol} / \mathrm{L}$ cytochalasin $D$ produced results similar to those of cytochala$\sin B$ (data not shown).
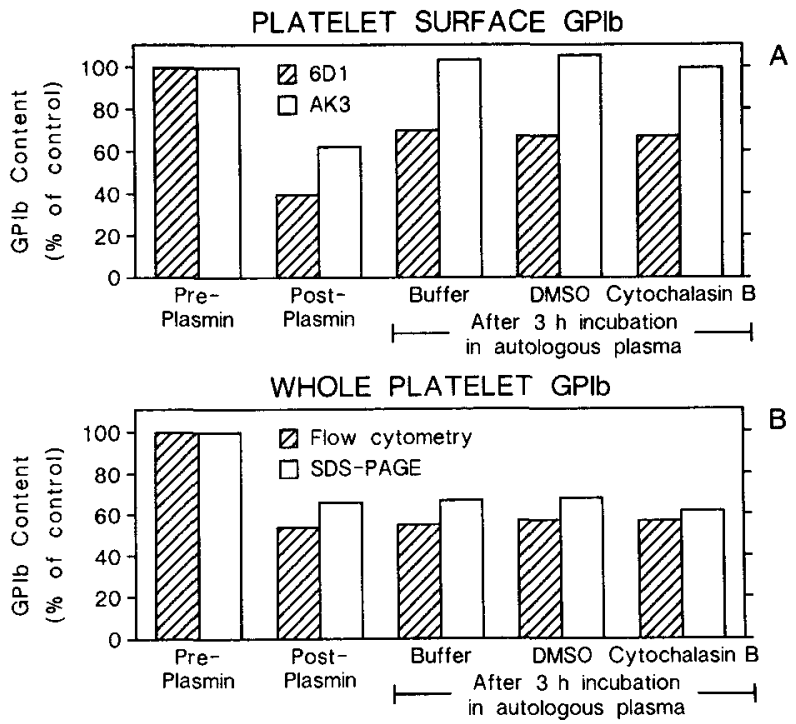

Fig 4. Effect of $6 \mu \mathrm{mol} / \mathrm{L}$ cytochalasin $B$ on the upregulation of platelet surface GPIb. Conditions were as described in legend to Fig 1 with plasmin $0.125 \mathrm{CU} / \mathrm{mL}$. (A) Platelet surface GPIb determined by flow cytometry with MoAbs 6D1 and AK3. (B) Whole platelet GPIb content determined by flow cytometry with MOAb 6D1 and SDS-PAGE. The experiment is representative of three separate experiments.
Because high concentrations of plasmin can induce platelet activation ${ }^{26}$ and platelet activation can result in decreased platelet surface GPIb expression, ${ }^{9-11}$ experiments were performed to determine whether plasmin was inducing platelet activation under the present experimental conditions (Fig 5). That the plasmin-induced loss of platelet surface expression of GPIb was not the result of platelet activation was confirmed because at the concentrations of plasmin used in this study $(\leq 0.125 \mathrm{CU} / \mathrm{mL})$ the decrease in platelet surface binding of the GPIb-specific MoAb 6D1 was not associated with an increase in platelet surface binding of the GMP-140 specific MoAb S12 (Fig 5). In contrast, thrombin-induced downregulation of platelet surface GPIb was associated with platelet activation, as evidenced by GMP-140 surface exposure (Fig 5).

\section{DISCUSSION}

This study showed that after proteolytic cleavage of platelet surface GPIb by plasmin, platelets can replenish their surface GPIb pool by recruiting GPIb molecules from an intraplatelet pool (or from a sequestered surface site). The replenishment of platelet surface GPIb was demonstrated by both an immunological method (flow cytometry with MoAbs) and a functional method (ristocetin agglutination). The ability of the flow cytometric method to analyze individual platelets ${ }^{20}$ enabled us to demonstrate that all platelets are able to upregulate platelet surface GPIb. That there was a redistribution of GPIb between the intraplatelet, platelet surface, and plasma (glycocalicin) pools was demonstrated by a reduction in whole platelet GPIb content (independently determined by ELISA, SDS-PAGE, and flow cytometry) in proportion with an increase in plasma glycocalicin concentration. Thus, the upregulation of platelet surface GPIb did not result from synthesis of new protein or uptake of plasma glycocalicin.

Together with previous studies, ${ }^{7,9-12}$ this study showed that GPIb molecules can traffic between intraplatelet and platelet surface pools. We recently demonstrated that in vitro platelet storage results in a redistribution of GPIb molecules in the direction of intraplatelet to platelet surface pools. ${ }^{7}$ In contrast, we $\mathrm{e}^{10}$ and other investigators $\mathrm{s}^{9,11}$ showed that thrombin induces a downregulation of platelet surface GPIb that is the 
Fig 5. Effect of plasmin treatment of platelets on the state of platelet activation. Washed platelets were incubated with either plasmin (1 hour. $22^{\circ} \mathrm{C}$ ) or $1.0 \mathrm{U} / \mathrm{mL}$ human $\alpha$-thrombin (10 minutes. $37^{\circ} \mathrm{C}$ ), and the platelet surface binding of MoAbs S12 (GMP-140 specific) and 6D1 (GPIb specific) was determined by flow cytometry. For S12, the fluorescence intensity of platelets incubated with thrombin $1.0 \mathrm{U} / \mathrm{mL}$ was assigned $100 \mathrm{U}$. For 6D1, the fluorescence intensity of resting platelets was assigned $100 \mathrm{U}$. Data are mean $\pm \operatorname{SEM}, n=3$.

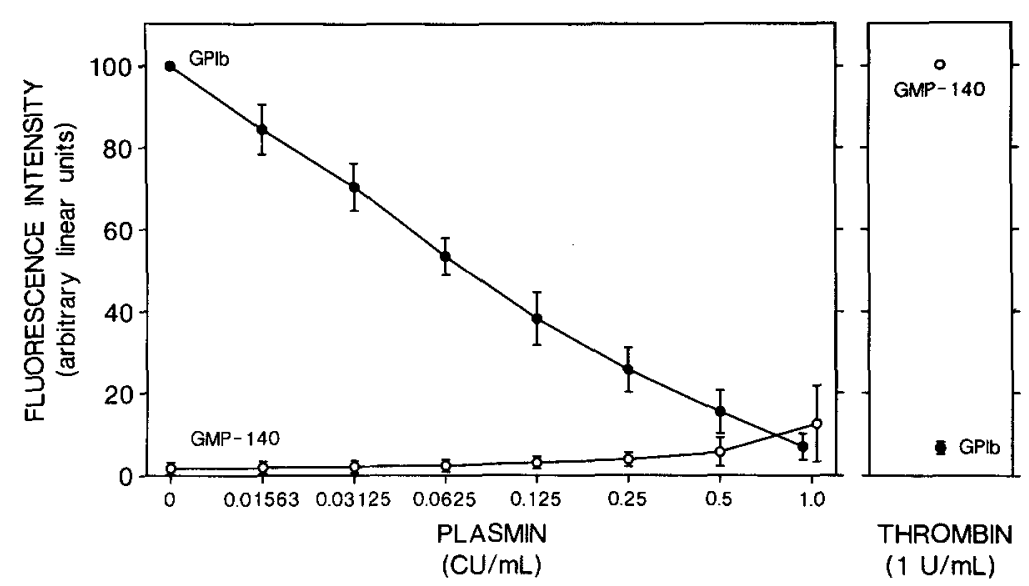

result of either translocation of platelet surface GPIb molecules to an intraplatelet pool (eg, the open canalicular system $)^{12}$ or sequestration of the platelet surface pool of GPIb. ${ }^{11}$

The platelet cytoskeleton, which is linked to platelet surface GPIb by actin-binding protein, ${ }^{24,27}$ appears to be involved in the control mechanism of the thrombin-induced downregulation of platelet surface GPIb, in view of the inhibitory effect of cytochalasins (ref. 11 and present study). The upregulation of platelet surface GPIb we describe was not mediated by the platelet microfilament system, however, as evidenced by the lack of effect of cytochalasins B and D. The upregulation of platelet surface GPIb was independent of (a) platelet activation (because, in contrast to the present findings, platelet activation results in downregulation of platelet surface GPIb, unchanged whole platelet GPIb content, and no release of glycocalicin ${ }^{9-11}$ ), (b) extracellular $\mathrm{Ca}^{2+}$ (as evidenced by the lack of inhibition by EDTA), and (c) cyclic AMP (as evidenced by the lack of inhibition by $\mathrm{PGE}_{1}$ ).

Possible control mechanisms for the upregulation of platelet surface GPIb include a transmembrane signalling event, a pH gradient through successive membrane compartments, and GTP-binding proteins. ${ }^{28}$ At the concentrations of plas$\min$ used $(0.03125$ to $0.125 \mathrm{CU} / \mathrm{mL})$, the plasmin-mediated cleavage of the $\mathrm{N}$-terminal protein portion of the $\alpha$-chain of GPIb (reported by MoAb 6Dl) was greater than the plasmin-mediated cleavage of the macroglycopeptide portion ${ }^{29}$ of the $\alpha$-chain of GPIb (reported by MoAbs WM23 and AK3) (Figs 2 and 4), consistent with the fact that the $\alpha$-chain of GPIb contains several cleavage sites for plasmin. ${ }^{14}$
The subsequent upregulation of platelet surface GPIb was complete as determined by WM 23 and AK 3 but incomplete as determined by 6D1 (Figs 2 and 4), raising the possibility that cleavage of (part of) the macroglycopeptide portion of the $\alpha$-chain of GPIb is necessary, and that cleavage of the $N$-terminal protein portion of the $\alpha$-chain of GPIb is insufficient, to initiate the signal for upregulation of platelet surface GPIb.

There are precedents for redistributions of GP receptor molecules between intraplatelet and platelet surface membrane pools. The GPIIb-IIIa complex (a receptor for fibrinogen, vWF, fibronectin, and vitronectin ${ }^{30}$ ) redistributes from an intraplatelet pool to the platelet surface pool in response to thrombin activation. ${ }^{31-33}$ Evidence has been presented for active cycling of GPIIb-IIIa between intraplatelet and platelet surface pools. ${ }^{34}$ GMP-140 (also known as PADGEM protein), a receptor that mediates the interaction of activated platelets with neutrophils and monocytes, ${ }^{35,36}$ is translocated from an intraplatelet $\alpha$-granule membrane pool to the platelet plasma membrane on platelet activation. ${ }^{18.37}$

Carefully performed in vivo studies will be necessary to determine whether the presently described plasmin-induced redistribution of platelet GPIb molecules can occur during clinical fibrinolytic states, eg, infusion of thrombolytic agents or disseminated intravascular coagulation.

\section{ACKNOWLEDGMENT}

We thank Dr Anita S. Kestin, Dr Peter H. Levine, James J. Hoogasian, Dr Philip P. Breitfeld, and Dr Peter E. Newburger for their support. We also thank Drs Michael Berndt, Barry Coller, and Rodger McEver for generously providing antibodies.

\section{REFERENCES}

1. Coller BS, Peerschke EI, Scudder LE, Sullivan CA: Studies with a murine monoclonal antibody that abolishes ristocetin-induced binding of von Willebrand factor to platelets: Additional evidence in support of GPIb as a platelet receptor for von Willebrand factor. Blood 61:99, 1983

2. Michelson AD, Loscalzo J, Melnick B, Coller BS, Handin RI: Partial characterization of a binding site for von Willebrand factor on glycocalicin. Blood 67:19, 1986

3. Vicente V, Houghten RA, Ruggeri ZM: Identification of a site in the $\alpha$ chain of platelet glycoprotein Ib that participates in von Willebrand factor binding. J Biol Chem 265:274, 1990
4. Takamatsu J, Horne MK, Gralnick HK: Identification of the thrombin receptor on human platelets by chemical crosslinking. $J$ Clin Invest 77:362, 1986

5. Harmon JT, Jamieson GA: The glycocalicin portion of platelet glycoprotein $\mathrm{Ib}$ expresses both high and moderate affinity receptor sites for thrombin. J Biol Chem 261:13224, 1986

6. George JN, Nurden AT, Phillips DR: Molecular defects in interactions of platelets with the vessel wall. $N$ Engl J Med 311:1084, 1984

7. Michelson AD, Adelman B, Barnard MR, Carroll E, Handin 
RI: Platelet storage results in a redistribution of glycoprotein Ib molecules. Evidence for a large intraplatelet pool of glycoprotein Ib. J Clin Invest 81:1734, 1988

8. Coller BS, Kalomiris E, Steinberg M, Scudder LE: Evidence that glycocalicin circulates in normal plasma. J Clin Invest 73:794, 1984

9. George JN, Pickett EB, Saucerman S, McEver RP, Kunicki TJ, Kieffer N, Newman PJ: Platelet surface glycoproteins. Studies on resting and activated platelets and platelet membrane microparticles in normal subjects, and observations in patients during adult respiratory distress syndrome and cardiac surgery. J Clin Invest 78:340, 1986

10. Michelson AD, Barnard MR: Thrombin-induced changes in platelet membrane glycoproteins Ib, IX, and IIb-IIIa complex. Blood 70:1673, 1987

11. George JN, Torres MM: Thrombin decreases von Willebrand factor binding to platelet glycoprotein Ib. Blood 71:1253, 1988

12. Nurden AT, Hourdille P, Heilmann E, Jallu V, Pintigny D, Clemetson K, Chevaleyre J, Vezon G: Thrombin induces a rapid redistribution of GPIb-IX complexes within the membrane systems of human platelets. Blood 74:129a, 1989 (abstr)

13. Adelman B, Michelson AD, Loscalzo J, Greenberg J, Handin RI: Plasmin effect on platelet glycoprotein Ib-von Willebrand factor interactions. Blood 65:32, 1985

14. Adelman B, Michelson AD, Greenberg J, Handin RI: Proteolysis of platelet glycoprotein Ib by plasmin is facilitated by plasmin lysine-binding regions. Blood 68:1280, 1986

15. Stricker RB, Wong D, Shiu DT, Reyes PT, Shuman MA: Activation of plasminogen by tissue plasminogen activator on normal and thrombasthenic platelets: Effects on surface proteins and platelet aggregation. Blood 68:275, 1986

16. Berndt MC, Gregory C, Kabral A, Zola H, Fournier D, Castaldi PA: Purification and preliminary characterization of the glycoprotein Ib complex in the human platelet membrane. Eur $\mathbf{J}$ Biochem 151:637, 1985

17. Berndt MC, Du X, Booth WJ: Ristocetin-dependent reconstitution of binding of von Willebrand factor to purified human platelet membrane glycoprotein Ib-IX complex. Biochemistry 27:633, 1988

18. Stenberg PE, McEver RP, Shuman MA, Jacques YV, Bainton DF: A platelet alpha-granule membrane protein (GMP-140) is expressed on the plasma membrane after activation. J Cell Biol 101:880, 1985

19. Hsu-Lin S-C, Berman CL, Furie BC, August D, Furie B: A platelet membrane protein expressed during platelet activation and secretion. Studies using a monoclonal antibody specific for thrombinactivated platelets. J Biol Chem 259:9121, 1984

20. Michelson AD: Flow cytometric analysis of platelet surface glycoproteins: Phenotypically distinct subpopulations of platelets in children with chronic myeloid leukemia. J Lab Clin Med 110:346, 1987

21. George JN, Thoi LL, McManus LM, Reimann TA: Isolation of human platelet membrane microparticles from plasma and serum Blood 60:834, 1982

22. Michelson AD, Barnard MR: The role of glycoprotein $\mathrm{Ib}$ in thrombin-induced modulation of platelet surface receptor expression. Blood 74:172a, 1989 (abstr)

23. Turner JR, Tartakoff AM, Berger M: A flow-cytometric method for the quantitative analysis of intracellular and surface membrane antigens. Methods Cell Biol 32:351, 1989

24. Fox JEB: Linkage of a membrane skeleton to integral membrane glycoproteins in human platelets. Identification of one of the glycoproteins as glycoprotein Ib. J Clin Invest 76:1673, 1985

25. Fox JEB, Phillips DR: Inhibition of actin polymerization in blood platelets by cytochalasins. Nature 292:650, 1981

26. Schafer AI, Maas AK, Ware JA, Johnson PC, Rittenhouse SE, Salzman EW: Platelet protein phosphorylation, elevation of cytosolic calcium, and inositol phospholipid breakdown in platelet activation induced by plasmin. J Clin Invest 78:73, 1986

27. Fox JEB: Identification of actin-binding protein as the protein linking the membrane skeleton to glycoproteins on platelet plasma membranes. J Biol Chem 260:11970, 1985

28. Lingappa VR: Intracellular traffic of newly synthesized proteins. Current understanding and future prospects. J Clin Invest 83:739, 1989

29. Okumura T, Lombart C, Jamieson GA: Platelet glycocalicin. II. Purification and characterization. J Biol Chem 251:5950, 1976

30. Phillips DR, Charo IF, Parise LV, Fitzgerald LA: The platelet membrane glycoprotein IIb-IIIa complex. Blood 71:831, 1988

31. Asch AS, Leung LLK, Polley MJ, Nachman RL: Platelet membrane topography: Colocalization of thrombospondin and fibrinogen with the glycoprotein IIb-IIIa complex. Blood 66:926, 1985

32. Wencel-Drake JD, Plow EF, Kunicki TJ, Woods VL, Keller DM, Ginsberg MH: Localization of internal pools of membrane glycoproteins involved in platelet adhesive responses. Am J Pathol 124:324, 1986

33. Woods VL, Wolff LE, Keller DM: Resting platelets contain a substantial centrally located pool of glycoprotein IIb-IIIa complex which may be accessible to some but not other extracellular proteins. J Biol Chem 261:15242, 1986

34. Wencel-Drake JD: Plasma membrane GPIIb/IIIa: Evidence for a cycling receptor pool. Blood 72:344a, 1988 (abstr)

35. Larsen E, Celi A, Gilbert GE, Furie BC, Erban JK, Bonfanti $R$, Wagner DD, Furie B: PADGEM protein: A receptor that mediates the interaction of activated platelets with neutrophils and monocytes. Cell 59:305, 1989

36. Hamburger SA, McEver RP: GMP-140 mediates adhesion of stimulated platelets to neutrophils. Blood 75:550, 1990

37. Berman CL, Yeo EL, Wencel-Drake JD, Furie BC, Ginsberg MH, Furie B: A platelet alpha granule membrane protein that is associated with the plasma membrane after activation. Characterization and subcellular localization of platelet activation-dependent granule-external membrane protein. J Clin Invest 78:130, 1986 